ARTICLE

https://doi.org/10.1038/s41467-020-14385-y

\title{
Tissue mechanics drives regeneration of a mucociliated epidermis on the surface of Xenopus embryonic aggregates
}

Hye Young Kim ${ }^{1,2,6 *}$, Timothy R. Jackson ${ }^{1,3,6}$, Carsten Stuckenholz (D) ${ }^{1}$ \& Lance A. Davidson (D) 1,4,5*

Injury, surgery, and disease often disrupt tissues and it is the process of regeneration that aids the restoration of architecture and function. Regeneration can occur through multiple strategies including stem cell expansion, transdifferentiation, or proliferation of differentiated cells. We have identified a case of regeneration in Xenopus embryonic aggregates that restores a mucociliated epithelium from mesenchymal cells. Following disruption of embryonic tissue architecture and assembly of a compact mesenchymal aggregate, regeneration first restores an epithelium, transitioning from mesenchymal cells at the surface of the aggregate. Cells establish apico-basal polarity within 5 hours and a mucociliated epithelium within 24 hours. Regeneration coincides with nuclear translocation of the putative mechanotransducer YAP1 and a sharp increase in aggregate stiffness, and regeneration can be controlled by altering stiffness. We propose that regeneration of a mucociliated epithelium occurs in response to biophysical cues sensed by newly exposed cells on the surface of a disrupted mesenchymal tissue.

\footnotetext{
${ }^{1}$ Department of Bioengineering, Swanson School of Engineering, University of Pittsburgh, Pittsburgh, PA 15213, USA. ${ }^{2}$ Center for Vascular Research, Institute for Basic Science (IBS), Daejeon, Republic of Korea. ${ }^{3}$ Essen BioScience, Ltd., Royston SG8 5WY, UK. ${ }^{4}$ Department of Developmental Biology, School of Medicine, University of Pittsburgh, Pittsburgh, PA 15260, USA. ${ }^{5}$ Department of Computational and Systems Biology, School of Medicine, University of Pittsburgh, Pittsburgh, PA 15260, USA. ${ }^{6}$ These authors contributed equally: Hye Young Kim, Timothy R. Jackson. *email: hyeyoung.pitt@gmail.com; lad43@pitt.edu
} 
X enopus embryos develop a mucociliary epidermis that functions much like respiratory epithelia in mammals ${ }^{1,2}$. Goblet cell progenitors develop exclusively from the epithelial surface layer, whereas multiciliated and other accessory cells derive from deep layer cells ${ }^{3-6}$ following Notch-mediated patterning ${ }^{7}$. Once committed, multiciliated and accessory cell precursors intercalate between goblet cell progenitors to establish a fully functioning mucociliary epidermis ${ }^{8}$. Multiciliated and accessory cells have been extensively studied, yet the conditions driving goblet cell specification and the role of the mechanical microenvironment in establishing those conditions remain unclear.

Physical forces contribute to many cell fate decisions. For instance, during the first fate decision in the mouse embryo, polarized cell contractility generates asymmetric cell tension between superficial outer and inner deep cells, leading to separation of trophectoderm and inner cell mass ${ }^{9}$. Physical forces, or the structures they generate also appear to pattern feather follicles in avian skin ${ }^{10}$. In vitro studies suggest mechanics of the tissue microenvironment, physically defined by factors such as stiffness, geometry, and substrate topology, can direct stem cell lineage specification and renewal ${ }^{11-13}$; however, the contribution of such physicomechanical cues to embryonic cell specification and regeneration in vivo is poorly understood. This gap between in vivo and in vitro studies reflects a paucity of model systems where tissue mechanics, cell behaviors, and cell fate choices can be studied quantitatively. With access to single cells, tissues, and whole embryos, Xenopus development can serve as a tractable model system for quantitative investigations on the role of mechanical cues in embryonic cell specification and regeneration.

In this paper we describe regeneration of a mucociliated epidermis on the surface of embryonic aggregates and the role of tissue mechanics in converting mesenchymal cells into epithelial goblet cell precursors. Aggregates are assembled from cells isolated from the deep layer of gastrula stage Xenopus ectoderm tissues. We use these aggregates to investigate tissue mechanical properties during goblet cell regeneration and find that tissue compliance, a measure of tissue softness inversely related to stiffness, decreases during the early phase of epithelization and coincides with the nuclear translocation of the putative mechanotransducer YAP. To rule out simple correlation we separately increased and decreased compliance of the nearsurface microenvironment. Using both small molecule inhibitors and mutant proteins we show that epithelialization can be blocked in high compliance or accelerated in low compliance environments. We show that mechanical cues alone can control regeneration of an embryonic mucociliary epithelium.

\section{Results}

Mesenchymal cells on surface transition to epithelial. Deep mesenchymal cells isolated from embryonic ectoderm and shaped into aggregates undergo an unexpected, but profound transformation into an epithelial cell type. Embryonic cells isolated from deep layers of the Xenopus laevis embryo-ectoderm, i.e. cells immediately below the simple epithelium of the ectoderm, generate compact aggregates (Fig. 1a). Simple epithelia of the superficial cell layer assemble tight junctions ${ }^{14}$ and keratin intermediate filaments ${ }^{15}$, distinguishing them from deep mesenchymal cells. Differences in adhesion allow efficient separation of a superficial layer from deep layer cells by brief exposure to calcium-magnesium-free media (Fig. 1a). Isolated deep ectoderm cells transferred to a non-adherent centrifuge tube rapidly adhere to each other in $<2 \mathrm{~h}$ to form a compact spherical aggregate. Immunostaining of F-actin and fibronectin (FN) show regions where surface cells extend $\mathrm{F}$-actin rich protrusions and assemble fibronectin fibrils (Fig. 1b, $1.5 \mathrm{~h}$ post aggregation, hpa). However, by $5 \mathrm{hpa}$, clusters of cells on the aggregate surface are clear of FN fibrils and protrusions, and adopt distinctive epithelial-like shapes with sharp cell boundaries marked by dense F-actin cables (Fig. 1b, arrows). By 24 hpa, the entire surface develops into a mature epidermis devoid of FN fibrils, with multiciliated cells indicated by dense apical actin (Fig. 1b, Supplementary Fig. 1a). To rule out contamination by epithelial cells during microsurgery we surface labeled the outer cell layer of embryos used for making aggregates (Fig. 1c) and found no contaminating cells (Fig. 1d). Phenotypic transitions occurred across a range of aggregate sizes (Fig. 1e, f) from large (cells from four embryo-ectoderm explants) to small (cells from $1 / 2$ of an embryo-ectoderm explant isolated from a single embryo). Thus, epithelial-like cells rapidly regenerate on the surface of a simple aggregate in the absence of externally provided factors.

Apico-basal polarity is established progressively in cells exposed on the surface of the aggregate. Cell membranes facing the external media accumulate aPKC, an early marker of apical polarity by $5 \mathrm{hpa}$; by $24 \mathrm{hpa}$, cell nuclei align in a pattern analogous to that seen in simple epithelia (Fig. 2a). By 5 hpa, epithelia-specific keratin intermediate filaments assemble along the apical surface; by $24 \mathrm{hpa}$, a mature epithelium forms with a dense keratin network (Fig. 2b). The epithelia-specific tight junction protein $\mathrm{ZO}-1$ also appears on the outer surface of a subpopulation of cells by $5 \mathrm{hpa}$ and covers the entire surface by 24 hpa (Fig. 2c). Live imaging of GFP-ZO1 at early stages reveals scattered puncta as well as circumapical junctions (Fig. 2c, d). Junctionally-localized GFP-ZO-1 appears on single cells and small groups as early as $2 \mathrm{hpa}$. The number of apically localized ZO- 1 cells increases over time, accounting for 10 to $15 \%$ of the surface area by 6 hpa (Fig. 2d, e).

The phenotypic transition to epithelial-like cells coincides with changes in expression of epithelia- (Cdh1, ZO-1, Krt12, Itln1) and mesenchyme-specific genes (FN, VimA, and Snail) in ectoderm (both superficial and deep), deep ectoderm, and superficial ectoderm tissues between 3 and 24 hpa (Fig. 2f). Over this time-span, the aggregate increases expression of epithelial marker genes E-cadherin (Cdh1; 6-fold), ZO-1 (5-fold), and keratin (Krt12; $>25$-fold) and the goblet cell marker intelectin 1 (Itln1; >1500-fold) while continuing to express mesenchymal genes. The expression of mesenchymal genes in the aggregate reflects the continued presence of deep mesenchymal cells, even as the surface epithelializes (Fig. 2f). Together, these results indicate that surface cells of deep ectoderm aggregates transform into an epithelial cell type and regenerate an epithelium.

New epithelium differentiates to mucociliary epidermis. How similar is this regenerated epithelial layer to the mature mucociliary epidermis of the embryo? Xenopus larval epidermis forms as deep progenitors of multiciliated cells, small secretory cells, and ionocytes radially intercalate into the outer layer formed by goblet cell precursors ${ }^{6}$. By $24 \mathrm{hpa}$, aggregates labeled with acetylated tubulin and F-actin reveal a pattern of multiciliated cells with dense apical actin cortex reminiscent of ciliated epithelium in similarly staged embryos (Fig. 2g). Furthermore, the ectoderm surface layer is dominated by mucus-secreting goblet cells marked by intelectin-1 (itln1 or Xeel; Fig. $2 \mathrm{~g}$ ). We further ruled out a source of goblet cells from Notch-dependent fate decisions that generate accessory cell types in vivo ${ }^{7}$ (Supplementary Fig. 1). Thus, the newly epithelialized surface of aggregates regenerates goblet cell precursors that are fully competent to differentiate into patterned larval epidermis analogous to epidermis observed in vivo. 
a
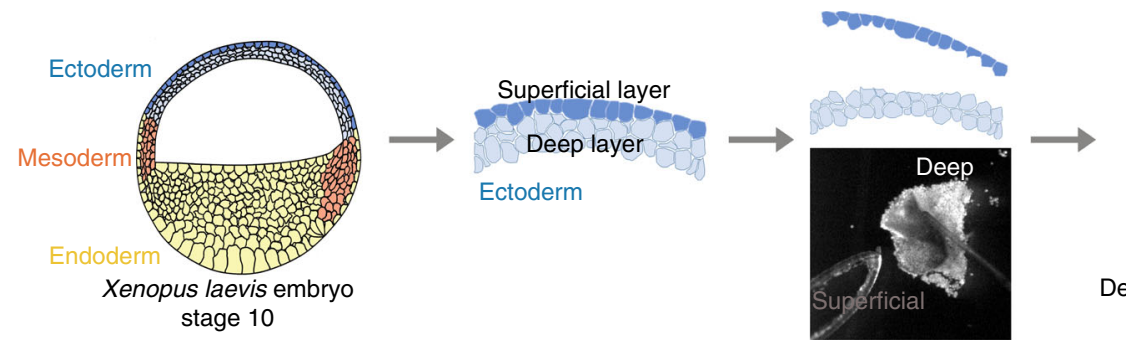

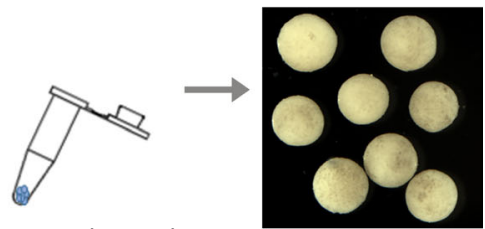

Deep ectoderm only
Deep ectoderm embryonic aggregates at $5 \mathrm{hpa}$
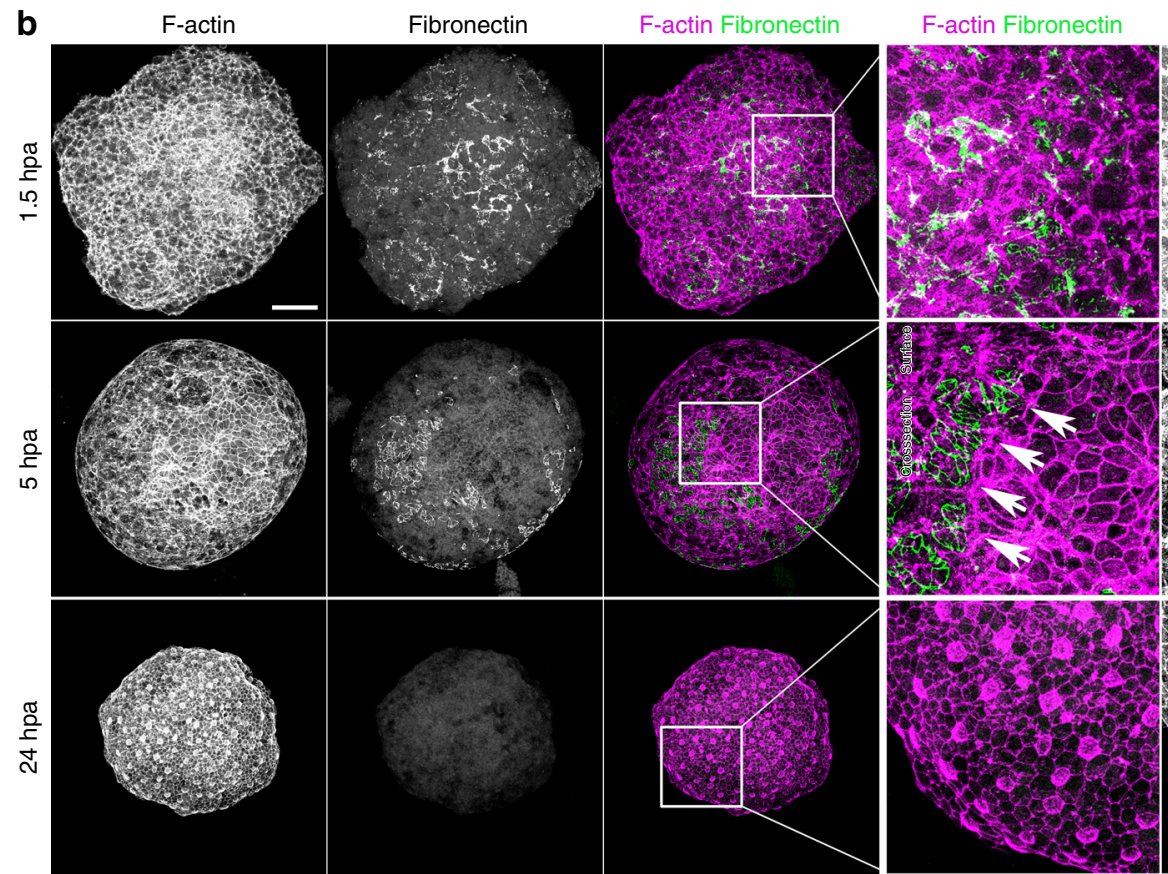

e
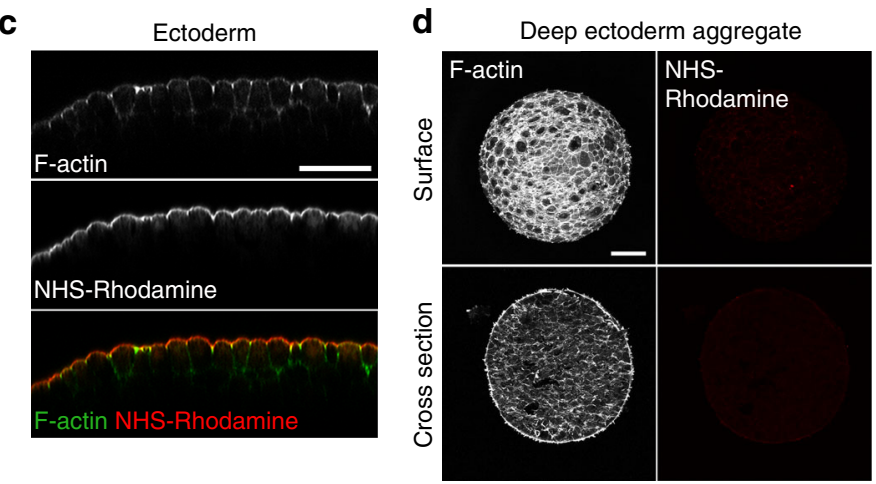

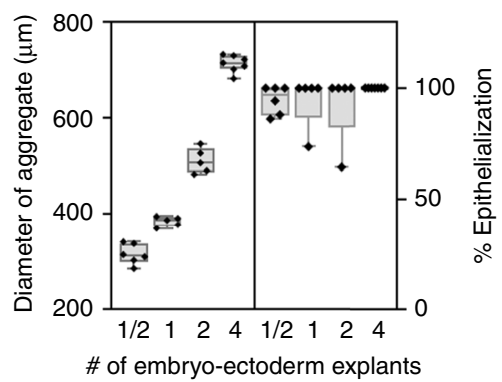

Fibronectin

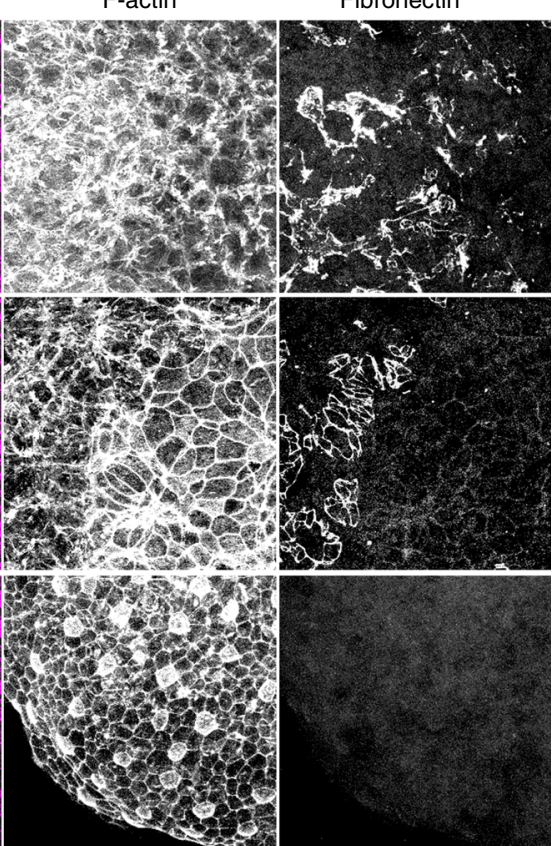

$\mathbf{f}$

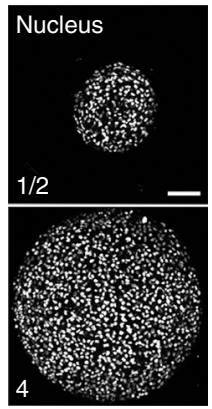

Fig. 1 Surface cells of deep ectoderm aggregates undergo epithelial-like phenotypic transition. a Schematic of the assembly of deep ectoderm cell aggregates from early Xenopus embryo (Stage 10). b Surface F-actin and fibronectin (FN) from maximum intensity projections at $1.5,5$, and $24 \mathrm{~h}$ post aggregation (hpa). Three panels on the right are higher resolution views of the inset region (white box) in the third column. Arrows indicate margin of FN where dense circumapical F-actin suggests epithelial cell phenotype. Scale bar for aggregate images is $100 \mu \mathrm{m}$. c Transverse sectional view through the ectoderm of NHS-Rhodamine surface-labelled embryos. Scale bar, $50 \mu \mathrm{m}$. Rhodamine is restricted to the apical surface of outer epithelial cells. d Deep ectoderm aggregates generated from NHS-Rhodamine surface-labelled embryos. Scale bar, $100 \mu \mathrm{m}$. Lack of rhodamine indicates absence of contaminating epithelia. e Percent of epithelial cell phenotype found on the surface of different-sized deep ectoderm aggregates at 24 hpa. Aggregates assembled with varying amounts of embryo-ectoderm explants ( $1 / 2$ explant, $n=6 ; 1$ explant, $n=5 ; 2$ explants, $n=5 ; 4$ explants, $n=8$ ). Box plot shows minimum, first quartile, median, third quartile, and maximum values. $\mathbf{f}$ Labeled nuclei shown in deep ectoderm aggregates from 1/2- and 4-embryo-ectoderm explant containing aggregates. Scale bar, $100 \mu \mathrm{m}$.

Epithelialization and YAP translocation as tissue stiffens. What triggers de novo epithelialization and goblet cell differentiation of the surface-layer cells in aggregates? Unlike deep ectoderm cells in vivo, deep ectoderm cells on the surface of aggregates are unconstrained by adjacent epithelia. Emergence of apparently random epithelial patches across the surface (Fig. 2c, d) suggests that cells respond to locally varying mechanical conditions. To test if cells might be responding to changes in their mechanical microenvironment, we analyzed the localization of Yes-associated protein 1 (YAP), a transcription factor whose nuclear translocation 

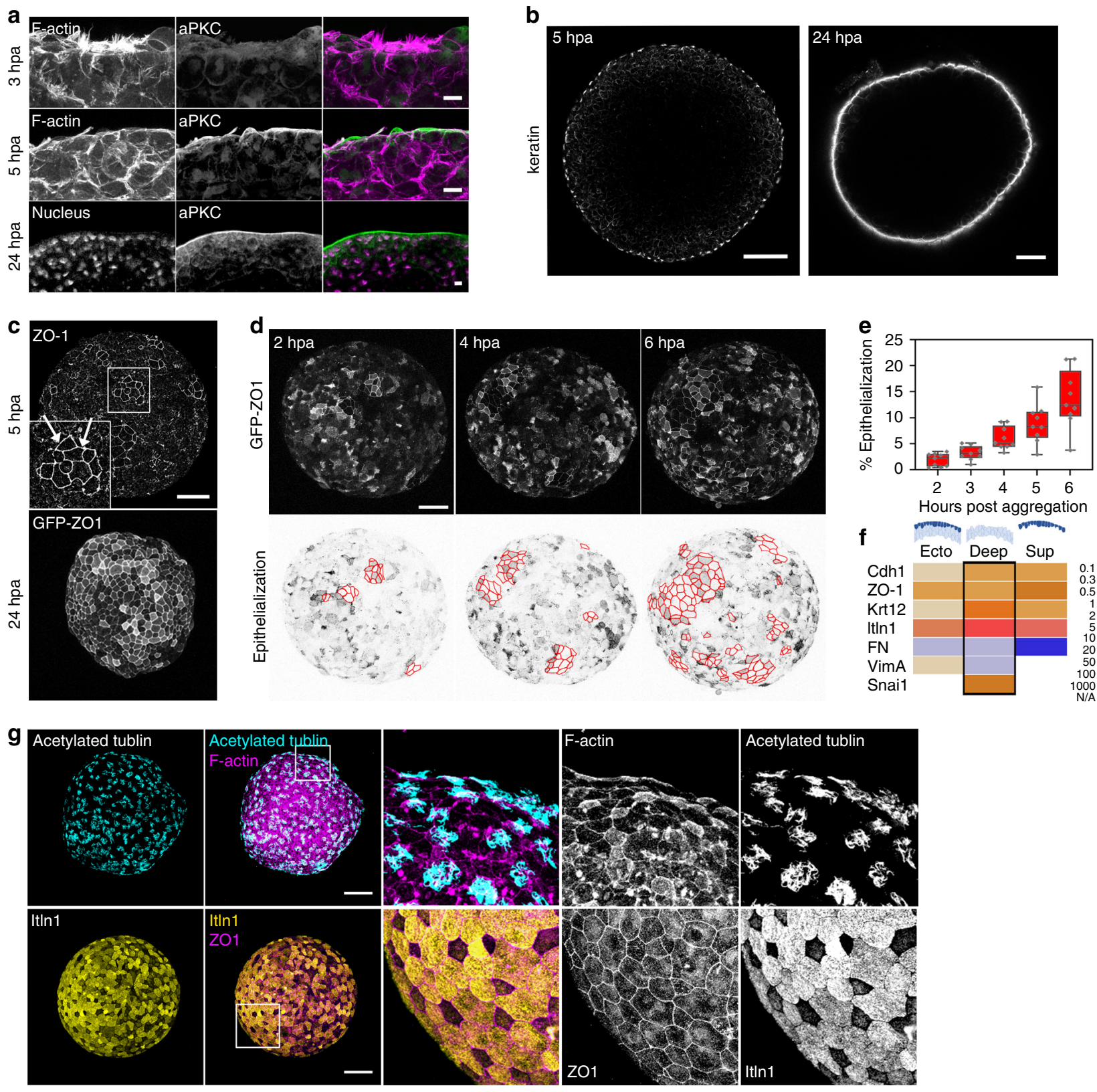

Fig. 2 Epithelialization precedes differentiation of mucus-secreting goblet cells. a Apical polarity protein aPKC localizes on the apical surface of aggregates by $5 \mathrm{hpa}$. Scale bar, $10 \mu \mathrm{m}$. b Apical localization of epithelial cytoskeleton keratin is restricted to the outer surface of deep ectoderm aggregates. Cross sectional view of aggregates at $5 \mathrm{hpa}$ (Scale bar, $100 \mu \mathrm{m}$ ) and $24 \mathrm{hpa}$ (Scale bar, $50 \mu \mathrm{m}$ ). c Maximum intensity projection of epithelial tight junctional protein ZO-1 expression in aggregates at $5 \mathrm{hpa} \mathrm{(top;} \mathrm{immunofluorescence} \mathrm{staining)} \mathrm{and} 24 \mathrm{hpa} \mathrm{(bottom;} \mathrm{GFP-ZO-1} \mathrm{expression).} \mathrm{Epithelialized} \mathrm{cells}$ are marked by arrows (inset). Scale bar, $100 \mu \mathrm{m}$. d Representative frames from a time-lapse sequence of an aggregate expressing GFP-ZO-1. Top panel: maximum intensity projection of GFP-ZO-1 shows cells undergo epithelialization (outlined with red on lookup-table-inverted images in lower panel) on the surface of aggregates from 2 to $6 \mathrm{hpa}$. Scale bar, $100 \mu \mathrm{m}$. e Percentage of cells having undergone epithelialization increases over time (9 aggregates tracked from three clutches). Box plot shows minimum, first quartile, median, third quartile, and maximum values. $\mathbf{f}$ qPCR expression profiling in aggregates made of ectoderm, deep layer, or superficial layer cells. Expression of epithelial (Cdh1, ZO-1, Krt12, and ItIn1) and mesenchymal (FN, VimA, and Snai1) genes are analyzed for CT-based fold changes from 3 hpa to 24 hpa. $\mathbf{g}$ At 24 hpa the deep ectoderm aggregate is covered by epithelial cells including differentiated mucus-secreting goblet cells (itln1) and radially intercalated multiciliated cells (acetylated tubulin). Scale bar, $100 \mu \mathrm{m}$.

in other cell types often correlates with changing mechanical conditions, e.g. stress fiber formation ${ }^{16}$, cell shape change and ECM rigidity ${ }^{17}$, and stretch ${ }^{18}$. YAP is found in the nucleus in cells on the surface of the aggregate (Fig. 3a) and its translocation to the nucleus depends on cell contractility (Fig. 3b). Nuclear levels of YAP increase in surface cells during the initial stages of epithelialization from $2 \mathrm{hpa}$ to $5 \mathrm{hpa}$ suggesting that surface cells experience changes in their mechanical environment as they establish apico-basal polarity (Fig. 3c). Since lower cell contractility reduced YAP nuclear translocation (Fig. 3b, c) we suspected that high levels of YAP translocation indicates an increase in tension at the aggregate surface.

To quantify mechanical changes in deep ectoderm aggregates, we measured the creep compliance, a function of tension and tissue stiffness, using micro-aspiration ${ }^{19}$. Application of a small negative pressure $(-10.1 \mathrm{~Pa})$ to a small patch on the surface of the 
a

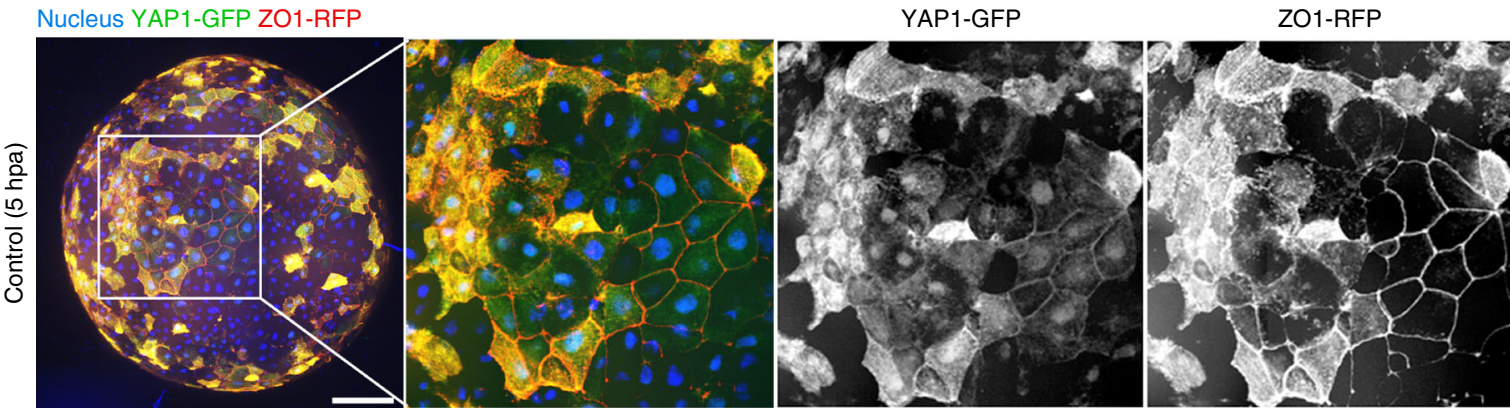

b

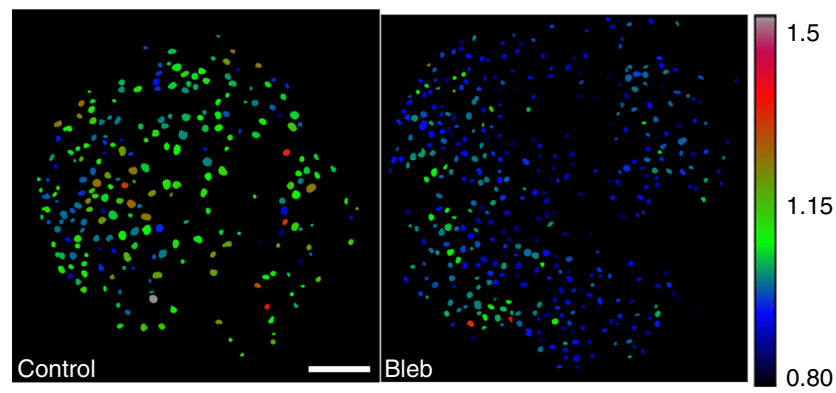

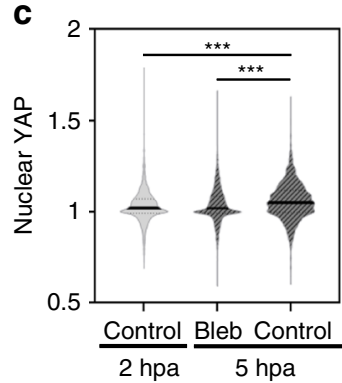

d

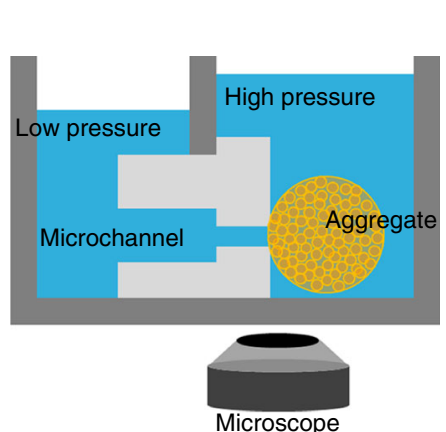

e

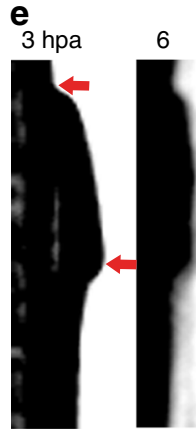

f

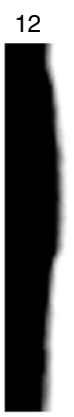

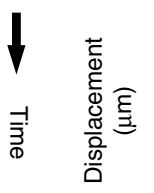
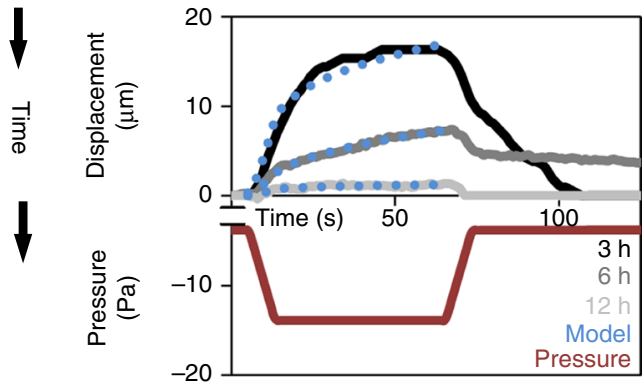

g

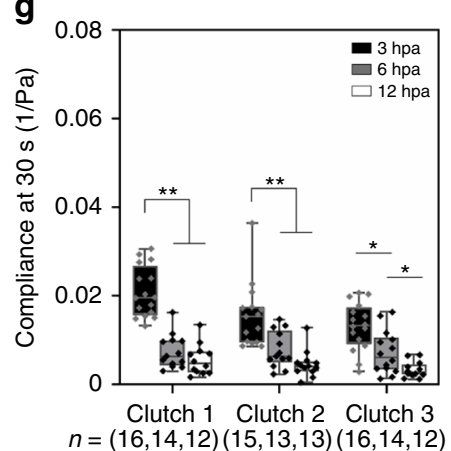

h

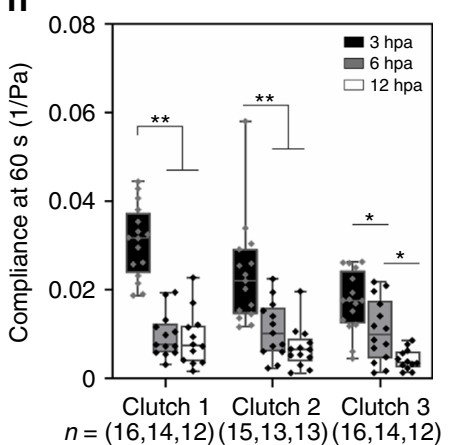

i

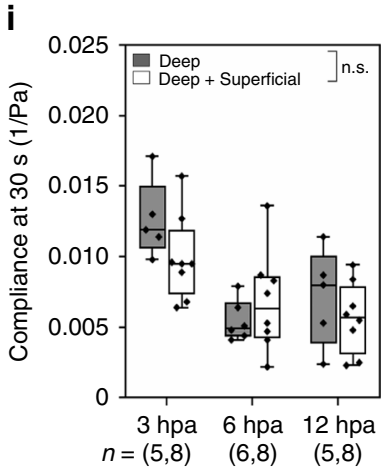

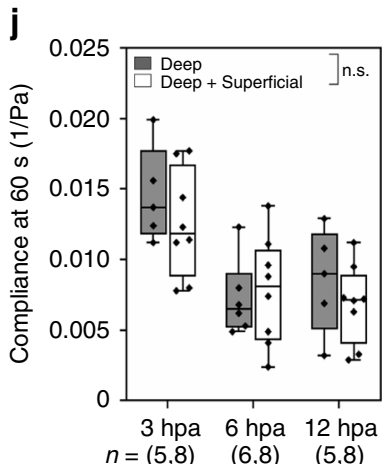

Fig. 3 YAP nuclear translocation and tissue stiffening both coincide with epithelialization. a Maximum intensity projection of deep ectoderm aggregate expressing YAP1-GFP and ZO-1-RFP and stained for nuclei. Scale bar, $100 \mu \mathrm{m}$. b Color coded nuclear YAP ratios for control and blebbistatin treated deep ectoderm aggregates at $5 \mathrm{hpa}$. Scale bar, $100 \mu \mathrm{m}$. c Nuclear YAP ratios of $5 \mathrm{hpa}$ aggregates $(n=2040$ nuclei from 7 aggregates $)$ are higher than blebbistatin-treated aggregates (3471 nuclei from 7 aggregates) and $2 \mathrm{hpa}$ aggregates (2167 nuclei from 7 aggregates). Statistical analysis from one-way ANOVA followed by Tukey multiple comparison test $\left({ }^{\star \star \star} P<0.001\right)$. d Schematic of micro-aspirator used to measure tissue compliance of aggregates by adjusting pressure at the opening of the microchannel (see Methods). e Representative kymographs of tissue displacement over the length of representative micro-aspiration experiments at 3,6, and $12 \mathrm{hpa}$. Red arrows indicate the time suction pressure is applied and then released. $\mathbf{f}$ Aspirated distances of an aggregates in (e) at 3 (black), 6 (dark gray), $12 \mathrm{hpa} \mathrm{(light} \mathrm{gray)} \mathrm{relative} \mathrm{to} \mathrm{the} \mathrm{pressure} \mathrm{applied} \mathrm{(red).} \mathrm{The} \mathrm{power-law} \mathrm{model} \mathrm{of} \mathrm{creep}$ compliance (blue dots) fit to this data. $\mathbf{g}$, h Creep compliance at 30 and $60 \mathrm{~s}$ indicating steady-state from micro-aspiration at 3 (black), 6 (gray) and 12 hpa (white). 12 to 16 aggregates were measured for each time point and repeated over three clutches. $\mathbf{i}, \mathbf{j}$ Creep compliance at 30 and $60 \mathrm{~s}$ from microaspiration of aggregates consisting of only deep mesenchymal cells (gray) or both deep mesenchymal and superficial epithelial cells (white) 3,6 , and $12 \mathrm{~h}$ post aggregation (one clutch, $n=5-8$ aggregates each). $\mathbf{g}-\mathbf{j}$ Box plots show minimum, first quartile, median, third quartile, and maximum values. Statistical analysis by Mann-Whitney U-test is shown as either not significant (n.s.) or by asterisk $\left({ }^{\star} P<0.05 ;{ }^{\star \star} P<0.01 ;{ }^{\star \star \star} P<0.001\right)$. 
aggregate reports compliance to a depth of $\sim 125 \mu \mathrm{m}$ (Fig. 3d-f). Deep ectoderm aggregates at 3, 6, and $12 \mathrm{hpa}$, representing phases before, during, and after the onset of epithelialization, respectively, exhibit significant and large decreases in compliance, i.e. increased stiffness, over the first $6 \mathrm{~h}$, at the same time as the onset of epithelization; compliance continues to decrease but appears to stabilize by later phases of differentiation (Fig. 3g, h). Comparing the compliance of early aggregates ( $3 \mathrm{hpa}$ ) with or without superficial epithelia indicates that stiffness increases are not merely a consequence of epithelialization (Fig. 3i, j). Nuclear translocation of YAP together with phased reduction in compliance of the aggregates suggests that changes in the mechanical microenvironment promote surface epithelization in aggregates.

Tissue mechanics controls epithelialization and regeneration. To understand how mechanics might control epithelialization and goblet cell differentiation, we sought to test the roles of actomyosin contractility and cell-cell adhesion, key mediators of tissue mechanics in embryos ${ }^{20}$. To reduce contractility we expanded our earlier perturbations of cell contractility by incubating aggregates in either a Myosin II inhibitor, blebbistatin $(100 \mu \mathrm{M})$, or a Rho-Kinase inhibitor, Y27632 $(50 \mu \mathrm{M})$. To reduce cell-cell adhesion we expressed mutant forms of C-cadherin (cdh3), the major cadherin expressed within deep ectoderm cells at these stages. Mutant forms lacked either the cytoplasmic $(\Delta \mathrm{C}$ $\mathrm{C}$-cadherin) or extracellular domains ( $\Delta \mathrm{E}-\mathrm{C}$-cadherin $)^{21}$. By 5 hpa $\sim 10 \%$ of the surface area of untreated aggregates adopt an epithelial phenotype (Fig. 4a, b) as quantified by the presence of circumapical F-actin, or ZO-1, along the boundary of the cells (Supplementary Fig. 2). Globally inhibiting contractility strongly reduces the epithelialized area, leaving the surface covered by Factin rich protrusions (Fig. 4a) like that seen at earlier stages (compare to Fig. 1b). To confirm the specific effects of the small molecule inhibitors of contractility, we expressed a mutant myosin binding subunit (MBS, MYPT1, or formally PPP1R12A), MBS $^{\mathrm{T} 695 \mathrm{~A}}$, which is known to inhibit contractility and subsequently increase tissue compliance ${ }^{22}$. Expression of $\mathrm{MBS}^{\mathrm{T} 695 \mathrm{~A}}$ blocked epithelialization (Fig. $4 \mathrm{a}, \mathrm{b}$ ). Reducing cell-cell adhesion by moderate overexpression of $\Delta \mathrm{E}$-C-cadherin also blocked epithelialization (Fig. 4a, b), as did moderate overexpression of $\Delta \mathrm{C}$ C-cadherin (Fig. 4a, b, $\Delta \mathrm{C}$-C-cadherin Myc positive); we note that wild-type cells (Myc negative) adjacent to mutant cells ( $\Delta \mathrm{C}$-C-cadherin, Myc positive) retain the ability to transition to and become epithelial (Supplementary Fig. 3). The reduced incidence of surface epithelialization following reductions in contractility or adhesion suggests both are required to advance epithelization in the aggregates.

Since reduced contractility inhibited epithelialization, we wondered whether increasing contractility might accelerate epithelialization. To increase contractility, we incubated aggregates with Calyculin A (10 nM), a myosin light chain phosphatase inhibitor known to increase contractility ${ }^{23,24}$. Alternatively, we expressed a potent activator of myosin contractility, a constitutively active mutant form of arhgef2 (arhgef2 ${ }^{\mathrm{C} 55 \mathrm{R}}$ ), a RhoAspecific guanine nucleotide exchange factor known to strongly lower tissue compliance ${ }^{25}$. Both treatments sharply increased epithelialization (1.6-fold by Calyculin A and 4.6-fold by arhgef 2 C55R; Fig. $4 \mathrm{a}, \mathrm{c})$. The effects of arhgef2 ${ }^{\mathrm{C} 55 \mathrm{R}}$ can be attributed to cell contractility, since its effects on epithelialization can be completely abolished by incubation with Y27632 (Supplementary Fig. S4a and b). Micro-aspiration further confirms that Calyculin A reduces compliance (Fig. 4d), and that both Blebbistatin (Fig. 4d) and MBST695A (Fig. 4e) increase tissue compliance compared to control aggregates in concordance with their effects on actomyosin contractility. Furthermore, reduction of actomyosin contractility with Y27632 blocks goblet cell differentiation (Fig. 4f), indicating that tissue mechanics plays a role in both epithelization and differentiation; however, it remains unclear whether epithelialization is a prerequisite for goblet cell differentiation. In summary, our data shows that contractility and tissue compliance regulate the onset of epithelialization and regeneration of a mucociliary epithelia in embryonic aggregates (Fig. 4g).

\section{Discussion}

Mesenchymal cell aggregates regenerate a superficial epithelial layer of goblet cell precursors in as little as $5 \mathrm{~h}$. This phenotypic transition occurs in the absence of externally provided factors and is independent of endogenous patterning processes such as Notch-pathways that normally generate accessory cells in the deep ectoderm ${ }^{26}$. Unlike progenitor cells within stratified epithelia, or pseudostratified epithelia ${ }^{27}$, native deep ectoderm cells in Xenopus remain in the deep layer through tadpole stages $^{28}$. By contrast, endogenous goblet cell precursors originate from, and are retained in the superficial layer of the ectoderm ${ }^{6}$. Thus, the programs driving epithelialization and regeneration of goblet cell precursors in aggregates appear to be distinct from endogenous developmental programs.

We are surprised that the genetic networks regulating goblet cell differentiation are distinct from the pathways generating multiciliated and accessory cells ${ }^{29}$. Our study suggests a novel goblet cell differentiation pathway that is Notch-independent and regulated by the mechanical microenvironment. It is interesting that multiciliated and accessory cells natively appear to undergo a form of single cell mesenchymal-to-epithelial transition ${ }^{30}$ as they intercalate between goblet cell precursors. The sensitivity of goblet cell precursor cells to mechanical cues may be responsible for pathological cases of basal cell differentiation where mucus-secreting goblet cells are over- or under-produced ${ }^{31}$.

The mechanical microenvironment surrounding progenitor cells can play a major role in determining their differentiation potential $^{11,32}$ and in maintaining stem cell populations ${ }^{32}$. What mechanical cues drive epithelialization and regeneration of goblet cells? Formation of an aggregate involves cell-cell contact, increasing cell-cell adhesion, and cell-autonomous actomyosin contractility. While all cells generate cortical contractions and membrane extensions into their surroundings, cells embedded within aggregates are bounded on all sides by cell-cell adhesions, whereas cells on the surface of aggregates have two distinct surfaces: one that faces other cells and is bounded by cell-cell adhesion, and one that is open to the culture media and unconstrained by cell-cell adhesion. As the aggregate compacts, cell projections along the open surface contact neighboring cells in a manner similar to filopodial extensions that accompany compaction early in mouse embryogenesis ${ }^{33,34}$. We propose that as cell aggregates become tightly adhered, they decrease in tissue compliance (Fig. 3d-j) and trigger the de novo establishment of an apico-basal axis in surface cells, which subsequently assemble epithelial-specific junctions. The progressive polarization and assembly of apical junctions parallels critical events in the earliest stages of mammalian embryogenesis as the inner cell mass segregates into epithelial and deeper mesenchymal cell layers, leading to the first steps of cell fate specification ${ }^{35}$. Based on our findings, we speculate that strong apico-basal cues might trigger YAP translocation to the nucleus but cannot rule out the possibility that polarization is a consequence of YAP nuclear translocation.

How do cells on the surface of the aggregate sense compliance? Time-lapse confocal sequences reveal that mesenchymal cells in the aggregate are very active, moving onto and off the surface over the course of an hour. Such tumbling behavior may limit 

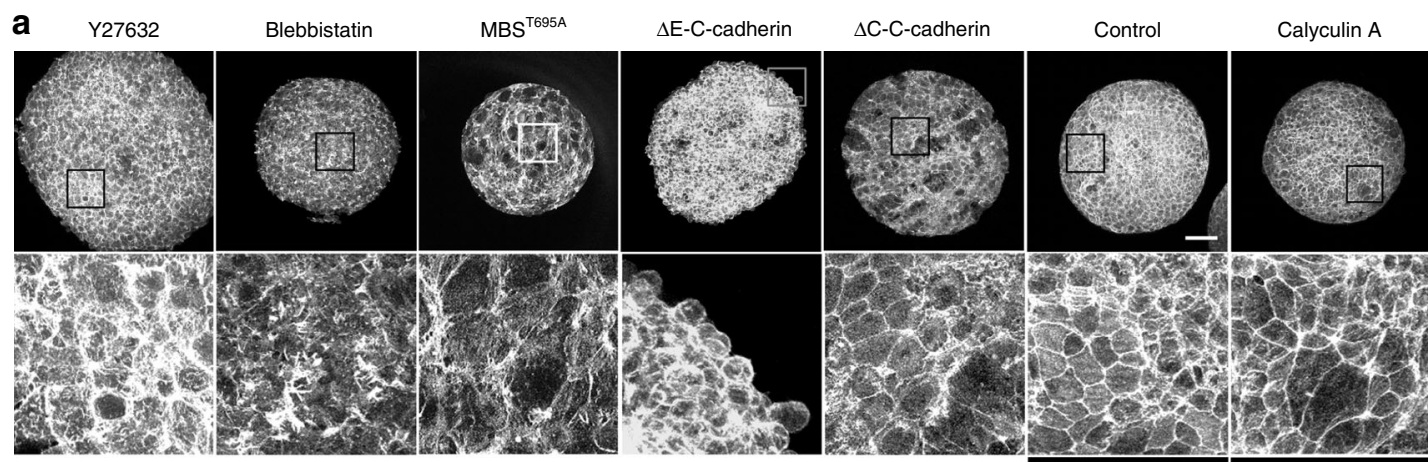

arhgef $^{\mathrm{C} 55 \mathrm{R}}$
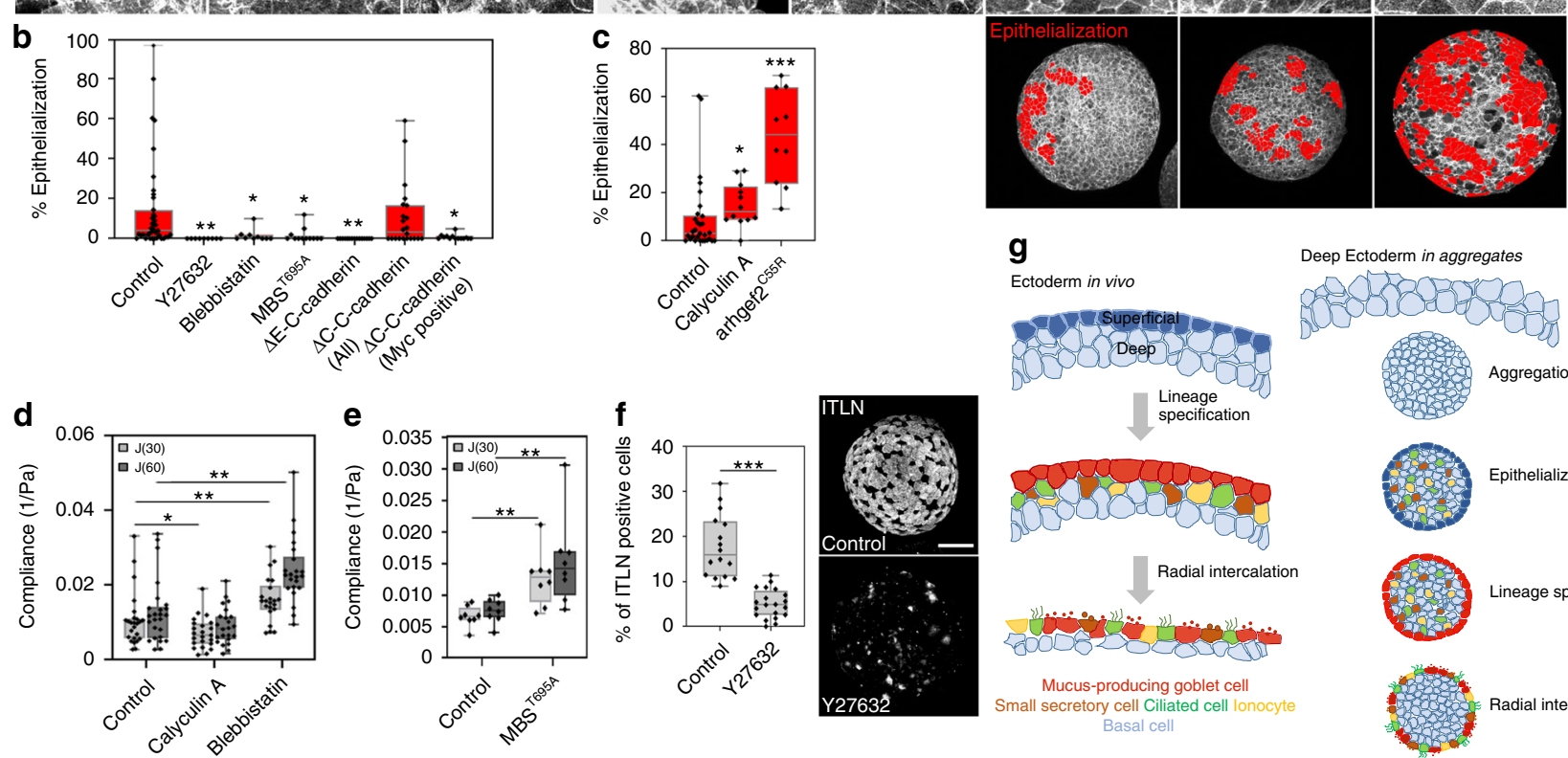

\section{g}
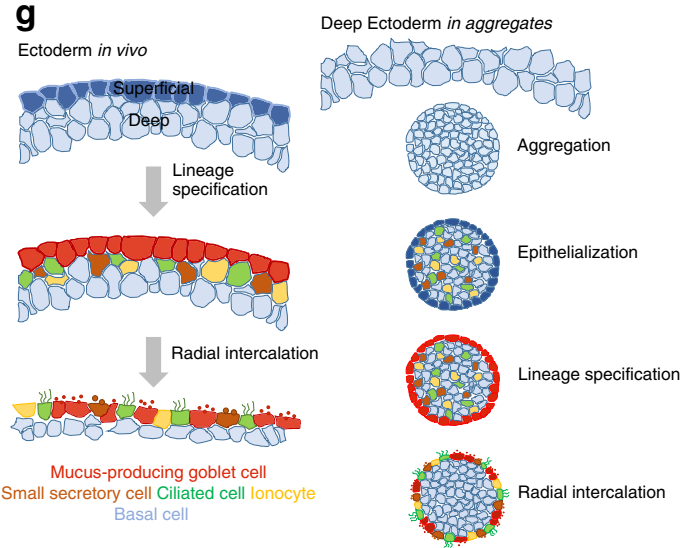

Fig. 4 Contractility and adhesion regulate surface epithelialization and goblet cell specification. a Maximum intensity projection of F-actin stained aggregates at $5 \mathrm{hpa}$. Insets (boxes) in top row shown in lower row. Scale bar for all top row is $100 \mu \mathrm{m}$. $\mathbf{b}$ Epithelialization (Control, $n=39$ ) is reduced after lowering contractility (Y27632, $n=9$; Blebbistatin, $\left.n=10 ; \mathrm{MBS}^{\mathrm{T} 695 \mathrm{~A}} ; n=12\right)$ and altering cell-cell adhesion $(\Delta \mathrm{E}-\mathrm{C}$-cadherin, $n=15$ and $\Delta \mathrm{C}-\mathrm{C}$-cadherin, $n=22$ ). Analysis for mosaic $\Delta C$-C-cadherin expression (anti-Myc positive) are shown in a separate bar. Kruskal-Wallis test, two-sided, $(P=<0.0001$ for $\mathrm{Y} 27632, P=0.015$ for Blebbistatin, $P=0.001$ for MBST695A, $P<0.0001$ for $\Delta \mathrm{E}$-C-cadherin, $P=0.147$ for $\Delta \mathrm{C}$-C-cadherin, $P=0.001$ for $\Delta \mathrm{C}$-C-cadherin (Myc positive)). c Epithelialization is increased after increasing contractility (control, $n=30$; Calyculin $A, n=12$; arhgef2 ${ }^{C 55 R}, n=10$ ). Red filled cells indicate epithelialized cells; surface areas are quantified in the graph. Significance of each treatment from the control is calculated using a Kruskal-Wallis H-test, two-sided; $P=0.046$ for Calyculin A, $P<0.0001$ for arhgef2. d Creep compliance at 30 and 60 s by micro-aspiration at 6 hpa after $4 \mathrm{~h}$ of small molecule inhibitor treatment. Data from four clutches were pooled with 22-25 aggregates per treatment. Statistical significance determined by Mann-Whitney U-test $\left({ }^{\star} P<0.05\right.$, $\left.{ }^{\star \star} P<0.01\right)$. (control, $n=25$; Calyculin $A, n=23$; Blebbistatin, $\left.n=22\right)$. e Creep compliance for MBS ${ }^{\top 695 A}$ expressing aggregates. Data from a single clutch with eight aggregates per treatment. Statistical significance determined by Mann-Whitney $U$-test $\left({ }^{\star} P<0.05\right.$, ${ }^{\star \star} P<0.01$ ). f Percentage of itln1 positive goblet cells quantified from two optical sections of $24 \mathrm{hpa}$ in deep ectoderm aggregates (control, $n=8 ;$ Y 27632 , $n=10$ ). Scale bar, $100 \mu \mathrm{m}$. Data from three clutches. Statistical analysis from unpaired t-test (two-tailed; $P<0.0001$ ). $\mathbf{g}$ Schematic contrasting developmental sequence of native embryonic ectoderm with in vitro regeneration of surface goblet cells in deep ectoderm aggregates. Regenerated epithelium serves as a substrate for radial intercalation of multiple cell types including multiciliated cells, ionocytes, and small secretory cells. Regenerated epithelial cells differentiate into mucus secreting goblet cells. b-f Box plots show minimum, first quartile, median, third quartile, and maximum values.

their ability to sense mechanical cues that initiate epithelialization. Reduced compliance, or increasing tissue solidity might reduce tumbling to produce a jammed state (e.g ref. ${ }^{36}$ ) that stabilizes cell contacts and allows a persistent polarizing signal. What might cells be sensing? Cells may sense reduced compliance through protrusions that extend over their neighbors. This mechanism might rely on cell adhesion complexes that are stabilized and initiate signaling. Alternatively, cells may sense compliance changes via basolateral contacts with neighbors; such contacts could stabilize as compliance decreases, allowing cells to establish and maintain apico-basal polarity. With changes in adhesive contacts, or persistence of apical polarity, surface cells could initiate epithelial and goblet cell transcriptional programs.
Xenopus ectoderm has been used historically to dissect fundamental signaling and patterning networks of development and stem cell differentiation ${ }^{37,38}$. More recently, biomechanical studies of Xenopus ectoderm have demonstrated how mechanics plays a direct role in regulating intercalation ${ }^{39}$, cell division ${ }^{40}$, epiboly ${ }^{41}$, and directional beating of multiciliated cells $s^{42,43}$. Our findings suggest analysis of regeneration of Xenopus ectoderm can contribute to our understanding of the role of mechanics in regulating cell fate. Mechanical and biophysical approaches using Xenopus will allow the field to revisit critical questions of patterning and induction to understand how mechanics integrates with canonical patterning systems. 


\section{Methods}

Embryos and embryonic cell aggregates. Embryos were obtained by standard methods; fertilized embryos were cultured in 1/3x modified Barth Solution (MBS) ${ }^{44}$ to the desired stage. To assemble the deep ectoderm aggregates, we first microsurgically isolated ectoderm explants from early gastrula embryos (Stage 10) in Danilchik's For Amy (DFA; 44) medium supplemented with antibiotic and antimycotic (Sigma). Next, ectoderm explants were transferred into calcium-magnesium-free DFA which allowed separation of deep and superficial layers of the ectoderm explant. After discarding the superficial layer, freshly isolated deep ectoderm cells were transferred to a PCR tube using a pipette. To provide a non-adherent surface for aggregation, PCR tubes were coated with $1 \%$ BSA overnight at $4{ }^{\circ} \mathrm{C}$. To confirm that our methods did not produce aggregates contaminated by epithelial cells from the superficial layer, the surface layer of whole embryos was labeled with NHS-Rhodamine (Thermo Scientific) ${ }^{45}$ and used to assemble deep ectoderm aggregates (Fig. 1c, d). Typically, 1-2 embryo-ectoderm explants were used to assemble a single aggregate except to make different sizes of aggregates (Fig. 1e, f). Deep ectoderm aggregates acquire a spherical shape within $2-3 \mathrm{~h}$ post aggregation (hpa), at which point they can be subjected to further procedures, including treatment with pharmacological inhibitors, measurement of compliance, and live imaging.

Research animal use. Embryos used in this study were obtained from a colony of Xenopus laevis frogs maintained at the University of Pittsburgh (USA) under the care of the Division of Laboratory Animal Research according to IACUC Protocol \#: 18022377 approved by the University of Pittsburgh Institutional Animal Care and Use Committee (PHS Assurance Number: D16-00118) as well as frogs maintained at the Institute for Basic Science (Republic of Korea) according to the protocol KAIST IACUC-(KA2017-22) / IBS IACUC (IBS 18-01).

Microinjection of localization and overexpression constructs. To visualize or overexpress proteins, mRNAs encoding the desired proteins were transcribed in vitro and injected into one- or two-cell stage fertilized embryos. GFP-ZO-1 was constructed by moving the entire eGFP-human TJP1 fusion protein obtained from Addgene (Plasmid \#30313; Addgene, Cambridge, MA) into pCS2+, mRFP-ZO-1 plasmid provided kindly by Dr. Ann Miller. To induce cell contractility, embryos were injected with arhgef2 ${ }^{\mathrm{C} 55 \mathrm{R}}$ at $\sim 87.5 \mathrm{pg}$ per embryo ${ }^{25}$. To alter cell-cell adhesion, $\Delta \mathrm{E}$-C-cadherin ( $1 \mathrm{ng}$ per embryo) and $\Delta \mathrm{C}$-C-cadherin ( 3.8 ng per embryo) were injected and ectopic gene expression was confirmed by both Myc staining and phenotype $^{21}$. Xenopus Yap1.S (formerly YAP1) was amplified from a Stage 10 whole-embryo cDNA library and subcloned C-terminal to eGFP into a pCS2+ vector (InFusion Cloning, Takara, Mountain View, CA). The constitutive active form of a myosin binding subunit (MBS T695A) was obtained from the open reading frame of human protein phosphatase 1 regulatory subunit $12 \mathrm{~A}$ (PPP1R12A, MBS) and amplified from pGEX-PPP1R12A wild type (a gift from Anne Brunet, Addgene plasmid 31669;46) and subcloned into pCS2+. The threonine at position 695 was mutated to alanine by PCR sewing using overlapping primers. All constructs were verified by sequencing at the University of Pittsburgh Genomics Research Core.

Histology and immunofluorescence. Aggregates were fixed with $4 \%$ paraformaldehyde and $0.25 \%$ glutaraldehyde in PBST (1x PBS with $0.1 \%$ Triton X-100) for $15 \mathrm{~min}$ at room temperature to visualize F-actin and fibronectin. For immunofluorescence of ZO-1, keratin, aPKC and Itln1, aggregates were fixed with ice cold Dent's fix (4:1 of Methanol:DMSO). Fixed aggregates were washed for 30 minutes with PBST and blocked with $10 \%$ goat serum in PBST for $1 \mathrm{~h}$ prior to antibody staining. Primary antibodies for FN (4H2), aPKC (nPKC (C-20) sc-216; Santa Cruz), acetylated tubulin (clone 6-11B-1; Sigma), ZO-1 (Invitrogen), keratin (1h5; Developmental Studies Hybridoma Bank), Myc (9E10; Millipore), and Itln1 (gift from Dr. Eamon Dubaissi, 11770-1-AP; Proteintech) were used at 1:200 dilution and incubated overnight on a nutator at $4{ }^{\circ} \mathrm{C}$. After washing, the samples were incubated with the appropriate secondary antibody at a 1:200 dilution overnight at $4{ }^{\circ} \mathrm{C}$. F-actin and cell nuclei were visualized with BODIPY-

FL-phallacidin (1:800) and either YO-PRO (1:10000, Invitrogen) or Hoechst 33342 (1:2000, Thermo Fisher), respectively. Cells were evaluated as having undergone epithelialization if they exhibited no F-actin protrusions and had strong circumapical F-actin, e.g. localization of F-actin to cell boundaries, which co-localize with ZO-1 (Supplementary Fig. 2).

For YAP nuclear localization studies, aggregates expressing YAP-GFP and ZO1-RFP were fixed using 4\% PFA in PBS for $15 \mathrm{~min}$ and stained with Hoechst. For analysis of the images, tiled images were stitched together using an ImageJ plugin ${ }^{47}$ and maximum projection images generated. The Hoechst channel was used to segment nuclei using a simple binary threshold. The YAP-GFP channel was used to segment and exclude cells not expressing fluorescent proteins. A custom macro quantified the mean nuclear intensity of YAP-GFP expression of each cell; the cytoplasmic intensity was obtained from an annular region surrounding each nuclei. YAP localization ratios (nuclear to cytoplasmic) are shown in Fig. 3b, c.
Pharmacological inhibitors. To alter cell contractility, aggregates at 2 hpa were incubated with Y27632 $(50 \mu \mathrm{M})$, Blebbistatin $(100 \mu \mathrm{M})$, or Calyculin A $(10 \mathrm{nM})$ until $5 \mathrm{hpa}$. Concentrations were chosen from prior studies in Xenopus $24,25,48-52$. All cytoskeletal inhibitors were purchased from Calbiochem (Millipore).

Compliance measurements using micro-aspiration. To quantify tissue mechanics, aggregates were placed in the high-pressure reservoir of a dual-reservoir micro-aspirator apparatus ${ }^{19,53}$. Aggregates were gently compressed using hair tools against a $125 \mu \mathrm{m}$ diameter channel cast across a PDMS block to form a seal across the opening of the channel (Fig. 3d). A pressure differential at the channel opening was controlled hydrostatically using a computer-controlled syringe pump. After calibrating the channel to obtain zero flow, a small baseline pressure of approximately $-3.8 \mathrm{~Pa}$ was applied in order to initiate suction and seal the aggregate onto the channel opening. The tissue aggregate was allowed to relax for $5 \mathrm{~min}$ before the 125-s micro-aspiration protocol was initiated. At the start of the protocol, the aggregate was imaged at 1 frame per second to obtain an initial aspiration length for the tissue. After 5 frames, the syringe pump removed $800 \mu \mathrm{L}$ of media from the low-pressure reservoir resulting in a $-10-\mathrm{Pa}$ suction pressure applied to the aggregate. After $60 \mathrm{~s}$ of $-10 \mathrm{~Pa}$ suction, $800 \mu \mathrm{L}$ of media was returned to the lowpressure reservoir to restore the baseline pressure. Imaging continued for an additional $60 \mathrm{~s}$ to confirm the aggregate was properly sealed onto the channel opening. When carrying out repeated measurements on the same sample, the aggregate was rotated to a different position. The tissue boundary during aspiration was tracked either manually or automatically with Canny-Deriche edge detection ${ }^{54}$. The aspirated length was measured and the data was fit to the power-law model for creep compliance, which has previously been shown to provide an adequate fit for embryonic tissue responses to stress-application ${ }^{19}$. Time-dependent compliance at $30 \mathrm{~s}$ (fast response) and $60 \mathrm{~s}$ (steady-state) is reported as the measurement of aggregate mechanical properties. Compliance calculations for each sample are independent of the magnitude of the pressure applied ${ }^{19}$. The suction pressure of $-10 \mathrm{~Pa}$ was chosen in order to sufficiently displace aggregate tissues within the resolution of our imaging system without exceeding the critical pressure, thus ensuring measurements are representative of tissue viscoelasticity ${ }^{55}$.

qPCR. To evaluate epithelial and mesenchymal gene expression in embryonic tissues, RNA was isolated using the Quick-RNA MiniPrep kit (Zymo Research) with 10 samples each of ectoderm, deep ectoderm aggregates, and superficial ectoderm aggregates at 3,6 , and $24 \mathrm{~h}$ post aggregation. RNA concentrations were measured using the NanoDrop and total RNA was used to create cDNA with the AccuScript High Fidelity 1st Strand cDNA Synthesis Kit (Agilent Technologies, Inc.). Forward and reverse primers (Supplementary Table 1) were designed for Xenopus laevis epithelial genes ZO-1, Cdh1, Itln1 and Krt12, mesenchymal genes FN, VimA and Snail and controls H4A. qPCR protocols were designed and carried out using the Bio-Rad iQ5 thermal cycler and PCR detection system. In all, $10 \mu \mathrm{L}$ reaction volumes were prepared according to SsoAdvanced Universal SYBR Green Supermix (Bio-Rad) instruction manual. In all, 40 amplification cycles were carried out followed by a melting curve analysis to ensure product purity. Categorization of gene expression at $3 \mathrm{hpa}$ was done using $C_{\mathrm{T}}$ values. Fold changes at $24 \mathrm{hpa}$ were calculated using the Livak method, using $\mathrm{H} 4$ as the reference gene and $3 \mathrm{hpa}$ as the calibrator $^{56}$. Results are consistent across triplicate experiments with two replicates.

Statistical analysis. Statistical differences of creep compliance among different time points post aggregation were calculated with ANOVA and planned repeated contrast. Stage dependence of compliance was measured over three clutches to account for clutch to clutch variation and potential staging errors. Statistical analysis of drug treatments was carried out using ANOVA and post-hoc analysis. ANOVA of drug treated aggregates showed data did not vary significantly by clutch $(P>0.05)$, so data was pooled from multiple clutches. Statistical tests of aggregate compliance or percentages of epithelialization were calculated using nonparametric methods using Mann-Whitney U-test (two cases) or Kruskal-Wallis H-test (multiple cases). Boxplots throughout paper describe the minimum, first quartile, median, third quartile, and maximum values. Statistical significance is shown as either not significant (n.s.) or by asterisk $\left({ }^{\star} P<0.05\right.$; ${ }^{*} P<0.01$; $\left.{ }^{* * *} P<0.001\right)$. All statistical analyses and plots were carried out with statistical software (IBM SPSS, version 22 or Graphpad Prism 8.3.0). Fluorescence images shown are representative of the larger samples used for quantitation.

Reporting summary. Further information on research design is available in the Nature Research Reporting Summary linked to this article.

\section{Data availability}

The data that support the findings of this study are available from the authors on reasonable request; see author contributions for specific data sets.

Received: 16 July 2015; Accepted: 9 December 2019; Published online: 31 January 2020 


\section{References}

1. Walentek, P. \& Quigley, I. K. What we can learn from a tadpole about ciliopathies and airway diseases: using systems biology in Xenopus to study cilia and mucociliary epithelia. Genesis 55, e23001 (2017).

2. Dubaissi, E. \& Papalopulu, N. Embryonic frog epidermis: a model for the study of cell-cell interactions in the development of mucociliary disease. Dis. Model Mech. 4, 179-192 (2011).

3. Quigley, I. K., Stubbs, J. L. \& Kintner, C. Specification of ion transport cells in the Xenopus larval skin. Development 138, 705-714 (2011).

4. Stubbs, J., Vladar, E., Axelrod, J. \& Kintner, C. Multicilin promotes centriole assembly and ciliogenesis during multiciliate cell differentiation. Nat. Cell Biol. 14, 140-147 (2012)

5. Walentek, P. et al. A novel serotonin-secreting cell type regulates ciliary motility in the mucociliary epidermis of Xenopus tadpoles. Development 141, 1526-1533 (2014).

6. Dubaissi, E. et al. A secretory cell type develops alongside multiciliated cells, ionocytes and goblet cells, and provides a protective, anti-infective function in the frog embryonic mucociliary epidermis. Development 141, 1514-1525 (2014).

7. Deblandre, G. A., Wettstein, D. A., Koyano-Nakagawa, N. \& Kintner, C. A two-step mechanism generates the spacing pattern of the ciliated cells in the skin of Xenopus embryos. Development 126, 4715-4728 (1999).

8. Stubbs, J. L., Davidson, L., Keller, R. \& Kintner, C. Radial intercalation of ciliated cells during Xenopus skin development. Development 133, 2507-2515 (2006).

9. Maitre, J. L. et al. Asymmetric division of contractile domains couples cell positioning and fate specification. Nature 536, 344-348 (2016).

10. Shyer, A. E. et al. Emergent cellular self-organization and mechanosensation initiate follicle pattern in the avian skin. Science 357, 811-815 (2017)

11. Engler, A. J., Sen, S., Sweeney, H. L. \& Discher, D. E. Matrix elasticity directs stem cell lineage specification. Cell 126, 677-689 (2006).

12. McBeath, R., Pirone, D. M., Nelson, C. M., Bhadriraju, K. \& Chen, C. S. Cell shape, cytoskeletal tension, and RhoA regulate stem cell lineage commitment. Developmental Cell 6, 483-495 (2004).

13. Kilian, K. A., Bugarija, B., Lahn, B. T. \& Mrksich, M. Geometric cues for directing the differentiation of mesenchymal stem cells. Proc. Natl Acad. Sci. USA 107, 4872-4877 (2010).

14. Merzdorf, C. S., Chen, Y. H. \& Goodenough, D. A. Formation of functional tight junctions in Xenopus embryos. Developmental Biol. 195, 187-203 (1998).

15. Jamrich, M., Sargent, T. D. \& Dawid, I. B. Cell-type-specific expression of epidermal cytokeratin genes during gastrulation of Xenopus laevis. Genes Dev. 1, 124-132 (1987).

16. Chanet, S. \& Martin, A. C. Mechanical force sensing in tissues. Prog. Mol. Biol. Transl. Sci. 126, 317 (2014).

17. Dupont, S. et al. Role of YAP/TAZ in mechanotransduction. Nature 474, 179-183 (2011).

18. Aragona, M. et al. A mechanical checkpoint controls multicellular growth through YAP/TAZ regulation by actin-processing factors. Cell 154, 1047-1059 (2013).

19. von Dassow, M., Strother, J. A. \& Davidson, L. A. Surprisingly simple mechanical behavior of a complex embryonic tissue. PLoS ONE 5, e15359 (2010).

20. Turlier, H. \& Maître, J.-L. In Seminars in Cell \& Developmental Biology, Vol. 47 110-117 (Elsevier, 2015).

21. Kurth, T. et al. Immunocytochemical studies of the interactions of cadherins and catenins in the early Xenopus embryo. Dev. Dyn. 215, 155-169 (1999).

22. Jackson, T. R., Kim, H. Y., Balakrishnan, U. L., Stuckenholz, C. \& Davidson, L. A. Spatiotemporally controlled mechanical cues drive progenitor mesenchymal-to-epithelial transition enabling proper heart formation and function. Curr. Biol. 27, 1326-1335 (2017)

23. Yam, P. T. et al. Actin-myosin network reorganization breaks symmetry at the cell rear to spontaneously initiate polarized cell motility. J. Cell Biol. 178, 1207-1221 (2007).

24. Kim, H. Y. \& Davidson, L. A. Punctuated actin contractions during convergent extension and their permissive regulation by the non-canonical Wnt-signaling pathway. J. Cell Sci. 124, 635-646 (2011).

25. Zhou, J., Kim, H. Y., Wang, J. H.-C. \& Davidson, L. A. Macroscopic stiffening of embryonic tissues via microtubules, Rho-GEF, and assembly of contractile bundles of actomyosin. Development 137, 2785-2794 (2010).

26. Werner, M. \& Mitchell, B. Understanding ciliated epithelia: the power of Xenopus. Genesis 50, 176-185 (2012).

27. Bragulla, H. H. \& Homberger, D. G. Structure and functions of keratin proteins in simple, stratified, keratinized and cornified epithelia. J. Anat. 214, 516-559 (2009).

28. Schroeder, T. E. Neurulation in Xenopus laevis. An analysis and model based upon light and electron microscopy. J. Embryol. Expt. Morphol. 23, 427-462 (1970).

29. Whitsett, J. A. Airway epithelial differentiation and mucociliary clearance. Ann. Am. Thorac. Soc. 15, S143-S148 (2018).
30. Kim, H. Y., Jackson, T. R. \& Davidson, L. A. On the role of mechanics in driving mesenchymal-to-epithelial transitions. Semin Cell Dev. Biol. 67, 113-122 (2017)

31. Rock, J. R., Randell, S. H. \& Hogan, B. L. Airway basal stem cells: a perspective on their roles in epithelial homeostasis and remodeling. Dis. Mod. Mech. 3, 545-556 (2010).

32. Gilbert, P. M. et al. Substrate elasticity regulates skeletal muscle stem cell selfrenewal in culture. Science 329, 1078-1081 (2010).

33. Fierro-Gonzalez, J. C., White, M. D., Silva, J. C. \& Plachta, N. Cadherin dependent filopodia control preimplantation embryo compaction. Nat. Cell Biol. 15, 1424-1433 (2013).

34. Maitre, J. L., Niwayama, R., Turlier, H., Nedelec, F. \& Hiiragi, T. Pulsatile cellautonomous contractility drives compaction in the mouse embryo. Nat. Cell Biol. 17, 849-855 (2015).

35. Korotkevich, E. et al. The apical domain is required and sufficient for the first lineage segregation in the mouse embryo. Dev. Cell 40, 235-247. e237 (2017)

36. Mongera, A. et al. A fluid-to-solid jamming transition underlies vertebrate body axis elongation. Nature 561, 1 (2018).

37. Kuroda, H., Fuentealba, L., Ikeda, A., Reversade, B. \& De Robertis, E. Default neural induction: neuralization of dissociated Xenopus cells is mediated by Ras/MAPK activation. Genes Dev. 19, 1022-1027 (2005).

38. Ariizumi, T. \& Asashima, M. In vitro induction systems for analyses of amphibian organogenesis and body patterning. Int J. Dev. Biol. 45, 273-279 (2001).

39. Sedzinski, J., Hannezo, E., Tu, F., Biro, M. \& Wallingford, J. B. Emergence of an apical epithelial cell surface in vivo. Dev. Cell 36, 24-35 (2016).

40. Stooke-Vaughan, G. A., Davidson, L. A. \& Woolner, S. Xenopus as a model for studies in mechanical stress and cell division. Genesis 55, e23004 (2017).

41. Stepien, T. L., Lynch, H. E., Yancey, S. X., Dempsey, L. \& Davidson, L. A Using a continuum model to decipher the mechanics of embryonic tissue spreading from time-lapse image sequences: An approximate Bayesian computation approach. PLoS ONE 14, 460774 (2019).

42. Chien, Y.-H., Keller, R., Kintner, C. \& Shook, D. R. Mechanical strain determines the axis of planar polarity in ciliated epithelia. Curr. Biol. 25, 2774-2784 (2015)

43. Chien, Y.-H., Srinivasan, S., Keller, R. \& Kintner, C. Mechanical strain determines cilia length, motility, and planar position in the left-right organizer. Dev. Cell 45, 316-330. e314 (2018)

44. Sive, H. L., Grainger, R. M., Harland, R. M. (eds.) Early development of Xenopus laevis: a laboratory manual. (Cold Spring Harbor Laboratory Press, Cold Spring Harbor, New York, 2000)

45. Edlund, A. F., Davidson, L. A. \& Keller, R. E. Cell segregation, mixing, and tissue pattern in the spinal cord of the Xenopus laevis neurula. Dev. Dyn. 242, 1134-1146 (2013)

46. Banko, M. R. et al. Chemical genetic screen for AMPKa2 substrates uncovers a network of proteins involved in mitosis. Mol. Cell 44, 878-892 (2011)

47. Preibisch, S., Saalfeld, S. \& Tomancak, P. Globally optimal stitching of tiled 3D microscopic image acquisitions. Bioinformatics 25, 1463-1465 (2009).

48. Zhou, J., Kim, H. Y. \& Davidson, L. A. Actomyosin stiffens the vertebrate embryo during critical stages of elongation and neural tube closure. Development 136, 677-688 (2009)

49. Zhou, J., Pal, S., Maiti, S. \& Davidson, L. A. Force production and mechanical adaptation during convergent extension. Development 142, 692-701 (2015).

50. Pfister, K., Shook, D. R., Chang, C., Keller, R. \& Skoglund, P. Molecular mode for force production and transmission during vertebrate gastrulation. Development 143, 715-727 (2016).

51. Rolo, A., Skoglund, P. \& Keller, R. Morphogenetic movements driving neural tube closure in Xenopus require myosin IIB. Dev. Biol. 327, 327-338 (2009).

52. Skoglund, P., Rolo, A., Chen, X., Gumbiner, B. M. \& Keller, R. Convergence and extension at gastrulation require a myosin IIB-dependent cortical actin network. Development 135, 2435-2444 (2008).

53. von Dassow, M. \& Davidson, L. A. Natural variation in embryo mechanics: gastrulation in Xenopus laevis is highly robust to variation in tissue stiffness. Dev. Dyn. 238, 2-18 (2009).

54. Schneider, C. A., Rasband, W. S. \& Eliceiri, K. W. NIH Image to ImageJ: 25 years of image analysis. Nat. Methods 9, 671-675 (2012).

55. Sato, M., Levesque, M. J. \& Nerem, R. M. An application of the micropipette technique to the measurement of the mechanical properties of cultured bovine aortic endothelial cells. J. Biomech. Eng. 109, 27-34 (1987).

56. Šindelka, R., Ferjentsik, Z. \& Jonák, J. Developmental expression profiles of Xenopus laevis reference genes. Dev. Dyn. 235, 754-758 (2006).

\section{Acknowledgements}

We thank Joe Shawky, Deepthi Vijayraghavan, Holley Lynch, Takehiko Ichikawa, and other members of the group for their comments and discussions. This work was supported by the National Science Foundation (CBET-1547790) and the National Institutes of Health (R01HD044750; R56HL13495). T.R.J. was supported in parts by the 
Cardiovascular Bioengineering Training Program (NIH NHLBI T32 HL076124). Any opinions, findings, and conclusions or recommendations expressed in this material are those of the authors and do not necessarily reflect the views of the National Science Foundation or the National Institutes of Health. Additionally HYK was supported by a Young Scientist Fellowship from Institute for Basic Science (IBS-R025-Y1). We thank the Developmental Studies Hybridoma Bank at the University of Iowa, supported by the NICHD of the NIH, for the anti-keratin antibody $1 \mathrm{H} 5$.

\section{Author contributions}

H.Y.K. and T.R.J. performed experiments and analyzed data; H.Y.K. conceived the model and designed experiments with L.A.D.; H.Y.K., T.R.J., L.A.D. wrote the paper. C.S. carried out cloning and assisted with qPCR.

\section{Competing interests}

The authors declare no competing interests.

\section{Additional information}

Supplementary information is available for this paper at https://doi.org/10.1038/s41467$020-14385-y$.

Correspondence and requests for materials should be addressed to H.Y.K. or L.A.D.
Peer review information Nature Communications thanks the anonymous reviewer(s) for their contribution to the peer review of this work.

Reprints and permission information is available at http://www.nature.com/reprints

Publisher's note Springer Nature remains neutral with regard to jurisdictional claims in published maps and institutional affiliations.

(c) (i) Open Access This article is licensed under a Creative Commons Attribution 4.0 International License, which permits use, sharing, adaptation, distribution and reproduction in any medium or format, as long as you give appropriate credit to the original author(s) and the source, provide a link to the Creative Commons license, and indicate if changes were made. The images or other third party material in this article are included in the article's Creative Commons license, unless indicated otherwise in a credit line to the material. If material is not included in the article's Creative Commons license and your intended use is not permitted by statutory regulation or exceeds the permitted use, you will need to obtain permission directly from the copyright holder. To view a copy of this license, visit http://creativecommons.org/ licenses/by/4.0/.

(C) The Author(s) 2020 